\section{Moulds and asthma: time for indoor climate change?}

\section{Ashley Woodcock}

\section{Effect of controlling mould in houses on respiratory health}

$\mathrm{T}$ he spectre of indoor moulds as a contributor to respiratory disease keeps raising its fruiting body and just won't go away. Numerous studies support a circumstantial and temporal link between high mould exposure and worse symptoms in susceptible individuals. However, it seems that the majority of respiratory physicians (at least in Europe) are at best non-believers. They are reluctant to consider moulds as important in patients with respiratory symptoms, rarely make specific enquiry, and almost never make attempts to reduce mould exposure. This contrasts with enthusiasm bordering on evangelism from some experts in the USA where huge litigation raises the stakes, with over 10000 cases pending and multi-million settlements already routine. ${ }^{1}$ In the past we have been hindered by profound ignorance of the biology of these important environmental contaminants. What do we know about indoor moulds, and how are they implicated in respiratory diseases, and specifically asthma? Should we be trying to reduce mould exposure for specific patients or the whole population and, if so, how?

Evidence for outdoor mould exposure and exacerbations of asthma is strong. For example, Alternaria is the dominant allergen in the mid west USA with strong temporal relationships between exposure and asthma severity. There are huge airborne spore counts (1000 times grass pollen counts) on peak days, associated with immediate worsening in sensitised subjects $^{2-5}$ and increased asthma deaths. ${ }^{6}$

However, assessing indoor mould exposure and relating exposure to worse respiratory disease is a much more complex issue. A range of mould species is undoubtedly associated with serious respiratory disease including infection (sinus and pulmonary) and allergy (allergic bronchopulmonary aspergillosis). In addition, there is strong evidence for a link between severe asthma and indoor mould sensitisation. ${ }^{7}$ But it has been unclear whether this association is an epiphenomenon reflecting worse non-specific atopy, or whether specific avoidance or treatment for fungi might be beneficial. Several confounding issues prevent an immediate conclusion: skin prick test solutions for moulds are crude, vary by manufacturer and may be nonspecific, ${ }^{8}$ and severe asthma could be a reflection of a severe reaction to environmental mould exposure or require colonisation of the airways (or skin). Novel and sensitive molecular methods may now help resolve this, since they identify apparently frequent fungal colonisation of sputum. This will avoid the need for culture and identification (which is highly skilled, selects fungi by their culture characteristics and may distort patterns of true exposure). A new acronym has recently been proposed for severe asthma with fungal sensitisation (SAFS); anecdotal responses to antifungal therapy have been observed, and a doubleblind randomised controlled trial of itraconazole is nearing completion.

The fungal kingdom is thought to contain over a million species, of which about 80000 have been named and about 600 species cause some form of human disease. In contrast, most infectious diseases of plants are fungal in origin. To date, very few airborne genera i.e. Alternaria, Aspergillus, Cladosporium, Botrytis and Penicillium have been implicated in allergic asthma, and a few more in extrinsic allergic alveolitis. A number of factors may make these species respiratory allergens. First, fungi such as Aspergillus and Penicillium have a spore size $(\sim 5 \mu \mathrm{m})$ within the respirable range, unlike other fungi which have much larger spores. Second, some fungi such as Aspergillus fumigatus which is capable of growth at $37^{\circ} \mathrm{C}$ can germinate and colonise the sinuses and airways, unlike Aspergillus clavatus, for example (the cause of malt workers' lung), which barely survives at $37^{\circ} \mathrm{C}$. Third, most fungal allergens fall into specific protein types, although a few key ones are unique to a species. A fumigatus is best explored and over 60 allergens are described with a wide range of biological effects. ' Proteases may be important in fungal antigen penetration of the airway mucosa but could also have a broader role in permitting sensitisation to other nonprotease environmental allergens (such as cat or dog proteins). ${ }^{10}$ Importantly, preformed allergen may be inhaled on the surface of hyphal fragments. Fourth, nonallergic mechanisms could act in parallel or independently. Glucan is a pro-inflammatory component of fungal cell walls ${ }^{11}$ and fungi also produce a range of volatile fungal mycotoxins, the importance of which we do not know with respect to respiratory disease.

Remarkably, we still do not understand what actually constitutes airborne mould exposure and where it comes from. The public and physicians alike consider indoor mould as that black (and virtually indestructible) rind in the shower, or where there is water penetration onto walls and ceiling often in low income households. However, there may be other important sources of mould. We have recently cultured a large range of moulds in pillows, ${ }^{12}$ together with volatile mycotoxins detected in low concentrations by mass spectrometry. The mould flora varied with type of pillow (synthetic vs feather). With the recent almost universal trend towards synthetic quilts and pillows, direct inhalation from bedding may be an important exposure in the context of allergy or infection in, for example, immunosuppressed patients. There is even evidence to suggest that Trichophyton nail infection can exacerbate asthma, which improves with specific treatment. ${ }^{13}{ }^{14}$ New techniques of exposure assessment using nasal samplers $^{15}$ and silent ion charged plates, ${ }^{16}$ together with multiplex technology for measuring multiple allergens simultaneously, ${ }^{1}$ provide hope for some future clarification of exposure. However, it is likely to be horrendously complex and, as a result, contentious.

In the absence of data on individual exposure, can we make any recommendations on control measures targeted at indoor moulds and improved health outcomes? Well, dampness is bad for asthma ${ }^{17-19}$ but good for mould growth. In this issue of Thorax, Burr and colleagues ${ }^{20}$ have examined asthma control after reducing dampness and removing mould in a randomised controlled trial in patients in South Wales with visible indoor mould in their homes (see page 767). Patients were randomised to either a simple intervention (mould removal plus fungicide applied to visible mould plus loft fan to promote ventilation) or control. At the end of the study the intervention group had lower humidity and about half the visible mould of the controls at 12 months ( $40 \%$ vs $78 \%$ ). Unexpectedly, there was a trend for less improvement in peak expiratory flow variability in the intervention group than in the control group, but there were significant improvements in symptoms and reduced medication use. This is an important study, but it must be interpreted with caution. There are many potential 
confounders, including reduction in passive smoke or mite allergen exposure, which could explain the improvement in respiratory symptoms. These types of study are extremely difficult, expensive and time consuming, but also virtually impossible to blind. Patient reporting bias could explain the soft positive outcomes, especially in conjunction with the low follow-up rate (6 months $\sim 55 \%, 12$ months $\sim 75 \%$ ). Even if the study is accepted as supporting mould control, we do not know which component of mould control is effective (removal, or fungicide, or increased ventilation, or perhaps all three combined). Or perhaps improving ventilation and reducing humidity is a good thing for respiratory health whatever the mechanism?

The answer to this question has been the subject of a truly landmark study from New Zealand ${ }^{21}$ which studied 1350 non-insulated homes with low income families. The houses were generally stand-alone wooden homes on piles, with heating of a living room only. Two-thirds of homes had damp and three-quarters had visible mould. The homes had at least one household member with respiratory symptoms in the last year or a history of asthma, pneumonia or chest infections. Homes were randomised to have ceiling insulation installed, draught stopping around windows and doors, and moisture impenetrable barriers fitted below the floors (cost $£ 700 /$ house) or to control. Over 12 months there were substantial (of the order of $50 \%$ ) improvements in selfrated health, wheezing and reduced time off work and school in the intervention group, with fewer visits to GP and hospital. Visible mould was reduced by $50 \%$. Again it is impossible to fully blind this study, but it was single blind and the size of the study and the size of improvements for a mix of hard and soft outcomes give it great weight. Essentially, the authors have identified an important and cost effective public health intervention. Whether it works by reducing mould exposure or whether mould is a bystander of housing quality is an open question.

So there is the challenge for any society with a social conscience. The New Zealand study needs to be reproduced around the world, accounting for local housing conditions and climate, to see if the results are transferable. In New Zealand the intervention not only improves respiratory health in a vulnerable part of society, it actually saves them money. Overall heating costs went down by $20 \%$, and that can't be bad for that other big environmental challenge-outdoor climate change!

Thorax 2007;62:745-746.

doi: $10.1136 /$ thx.2007.079699

Correspondence to: Dr Ashley Woodcock, University of Manchester, South Manchester University Hospital Foundation Trust, Manchester M23 9LT, UK; ashley.a.woodcock@manchester. ac.uk

Competing interests: None.

\section{REFERENCES}

1 Chapman MD. Challenges associated with indoor moulds: health effects, immune response and exposure assessment. Med Mycol 2006;44:S29-32.

2 Salvaggio J, Seabury J, Schoenhardt E. New Orleans asthma. V. Relationship between charity hospital admission rates, semiquantitative pollen and fungal spore counts and total particulate aerometric sampling data. J Allergy Clin Immunol 1971;48:96-114.

3 Newson R, Strachan D, Corden J, et al. Fungal and other spore counts as predictors of admissions for asthma in the Trent region. Occup Environ Med 2000;57:786-92.

4 Rosas I, McCartney HA, Payne RW, et al. Analysis of the relationships between environmental factors (aeroallergens, air pollution, and weather) and asthma emergency admissions to a hospital in Mexico City. Allergy 1998;53:394-401.
5 Salvaggio J, Aukrust L. Mould-induced asthma. J Allergy Clin Immunol 1981;68:327-46

6 Targonski PV, Persky WW, Ramekrishnan V. Effect of environmental molds on risk of death from asthma during the pollen season. J Allergy Clin Immunol 1995;95:955-61.

7 O'Driscoll RB, Hopkinson L, Denning DW. Mold sensitisation allergy is common amongst patients with severe asthma requiring multiple hospital admissions. BMC Pulm Med 2005;5:4.

8 Aas K, Leegaard J, Aukrust L, et al. Immediate type hypersensitivity to common moulds. Comparison of different diagnostic materials. Allergy 1980;35:443-51.

9 Denning DW, O'Driscoll BR, Hogaboam C, et al. The link between fungi and severe asthma: a summary of the evidence. Eur Respir J 2006;27:615-26.

10 Goplen NP, Liang Q, Morimoto Y, et al. Development of a mouse model of chronic experimental asthma. Proceedings of American Thoracic Society, 2006;A287.

11 Fogelmark B, Thorn J, Rylander R. Inhalation of (13) beta-D glucan causes airway eosinophilia. Mediators Inflamm 2001;10:13-9.

12 Woodcock A, Steele N, Moore CB, et al. Fungal contamination of bedding. Allergy 2006:61:140-2.

13 Ward GW, Karlsson G, Rose G, et al. Trichophyton asthma: sensitization of bronchi and upper airways to dermatophyte antigen. Lancet 1989;1:859-62.

14 Ward GW Jr, Woodfolk JA, Hayden ML, et al. Treatment of late-onset asthma with fluconazole. $J$ Allergy Clin Immunol 1999;104:541-6.

15 Green BJ, O'Meara T, Sercombe J, et al. Measure of personal exposure to airborne aeromycota in north New South Wales Australia. Ann Agric Environ Med 2006;13:225-34.

16 Custis N, Woodfolk JA, Vaughan JW, et al. Quantitative measurement of airborne allergens from dust mites, dogs, and cats using an ion charging device. Clin Exp Allergy 2003;33:986-91.

17 Nicolai T, Illi S, von Mutius E. Effect of dampness at home in childhood on bronchial hyper-reactivity in adolescence. Thorax 1998;53:1035-40.

18 Gunnbjornsdottir MI, Norback D, Plaschke P, et al. The relationship between indicators of building dampness and respiratory health in young Swedish adults. Respir Med 2003;97:302-7.

19 Williamson IJ, Martin CJ, McGill G, et al. Damp housing and asthma: a case-control study. Thorax 1997;52:229-34.

20 Burr ML, Matthews IP, Arthur RA, et al. Effects on patients with asthma of eradicating visible indoor mould: a randomised controlled trial. Thorax 2007;62:767-72.

21 Howden-Chapman P, Mathson A, Crane J, et al. Effect of insulating existing houses on health inequality: cluster randomised design study in the community. BMJ 2007;334:460-4.

\section{Maternal diet vs lack of exposure to sunlight as the cause of the epidemic of asthma, allergies and other autoimmune diseases}

\section{Scott T Weiss, Augusto A Litonjua}

\section{Role of vitamin D deficiency in allergic and autoimmune diseases}

A sthma is occurring in epidemic proportions with more than 300 million affected subjects worldwide. In almost

all cases the disease has its onset in early childhood, with $80-90 \%$ of all cases initially being diagnosed before the age of 6 years. ${ }^{12}$
It was not always so. In the early 1970s the prevalences of asthma and allergy were roughly half of what they are today, and although the onset of the asthma epidemic started insidiously and cannot be precisely documented, it has several interesting and important features that have defied a unified explanation until now. There is clearly a North/South equatorial gradient with Western industrialised countries furthest away from the equator (New Zealand, Australia, the UK) having the highest prevalence worldwide. There is also a clear urban/rural gradient among poorer Third World countries, and a First (industrialised) World/Third World gradient with the lowest asthma prevalence occurring in rural areas in Third World societies. A very important feature of the epidemic is that it is not only asthma that has increased. A host of 